\title{
Biological Effect and Mechanism of the miR-23b-3p/ANXA2 Axis in Pancreatic Ductal Adenocarcinoma
}

\author{
Dan-ming Wei Yi-wu Dang Zhen-bo Feng Lu Liang Lu Zhang Rui-xue Tang \\ Zhi-min Chen Qiao Yu Yi-chen Wei Dian-zhong Luo Gang Chen
}

Department of Pathology, First Affiliated Hospital of Guangxi Medical University, Nanning, China

\section{Key Words}

miR-23b-3p - ANXA2 - pancreatic ductal adenocarcinoma

\begin{abstract}
Background/Aims: Accumulating evidence strongly suggests that microRNAs (miRNAs) modulate the expression of known tumor suppressor genes and oncogenes. In the present study, we found that the proliferation and invasion ability of pancreatic ductal adenocarcinoma (PDAC) cells were significantly suppressed by the overexpression of miR-23b-3p. In addition, there are miR-23b-3p binding sites in annexin A2 (ANXA2). Here, we investigated whether miR-23b-3p had an impact on the progression and metastasis of PDAC by targeting ANXA2. Methods: Cell proliferation, migration, and invasion, and cell cycle assays were performed to explore the effect of miR-23b-3p on various malignant phenotypes of pancreatic cancer cells. The size of tumors was observed following miR-23b-3p overexpression in an in vivo chick chorioallantoic membrane assay. Dual-luciferase reporter, quantitative real-time PCR, western blot, and immunohistochemical analyses were used to validate the relationship between miR$23 b-3 p$ and ANXA2 in vitro. Results: We observed that miR-23b-3p could bind specifically to the $3^{\prime}$ untranslated region of ANXA2 and inhibit its expression. MiR-23b-3p overexpression downregulated the expression of ANXA2 mRNA in PDAC cells and limited the size of tumors or even prevented tumor formation. In addition, there was a negative correlation between miR-23b-3p expression and ANXA2 protein expression in clinical specimens. Conclusion: MiR-23b-3p inhibits the development and progression of PDAC by regulating ANXA2 directly.
\end{abstract}

\section{Introduction}

Pancreatic cancer (PC) is an aggressive malignancy with a poor prognosis [1]. With a 5 -year survival rate of $8.0 \%, \mathrm{PC}$ is currently the fourth leading cause of cancer-related death in the US [2]. It has one of the worst outcomes and is the sixth leading cause of cancerrelated death in China [3]. Approximately $90 \%$ of cases with the disease have pancreatic D.-m. Wei and Y.-w. Dang contributed equally to this work.

\begin{tabular}{ll}
\hline Gang Chen & Department of Pathology, First Affiliated Hospital of Guangxi Medical University \\
and Dian-zhong Luo & Nanning, Guangxi Zhuang Autonomous Region 530021 (China) \\
& E-Mail chengang@gxmu.edu.cn; 13878802796@163.com
\end{tabular}




\section{Cellular Physiology Cell Physiol Biochem 2018;50:823-840

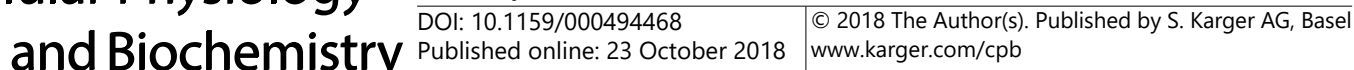 \\ Wei et al.: miR-23b-3p/ANXA2 in PDAC}

ductal adenocarcinoma (PDAC) [4]. The devastating malignant behavior of PDAC is related to its biological characteristics. It is usually asymptomatic at first and becomes apparent only after the tumor has infiltrated the surrounding tissues or metastasized to distant organs [5]. Thus, PDAC is considered an aggressive malignancy, and further studies of the molecular mechanisms underlying its aggressive nature are required to develop an effective treatment.

MicroRNAs (miRNAs) are a class of small, non-coding RNAs of approximately 17-22 nucleotides in length [6]. They regulate the expression of target genes by binding to complementary sequences on mRNAs [7, 8]. Accumulating evidence strongly suggests that miRNAs modulate the expression of known tumor suppressor genes and oncogenes and function as tumor suppressor miRNAs or oncomiRNAs [9]. Recently, a large number of miRNAs have been demonstrated to be aberrantly expressed in PDAC and found to be associated with its initiation and progression [10-12].

MiR-23b-3p, formerly known as miR-23b, is located on human chromosome 9q22.32 [13]. Our previous studies found that miR-23b-3p expression was lower in formalinfixed, paraffin-embedded PDAC tissues than in adjacent normal pancreatic tissues. It was also lower in PDAC cells than in normal pancreatic HPDE6C-7 cells. Higher miR-23b-3p expression was correlated with smaller tumor size, lower invasion, and longer diseasespecific survival. Moreover, multivariate Cox regression analysis revealed that miR-23b-3p was an independent factor in the prognosis of PDAC [14]. On the basis of bioinformatics predictions (http://starbase.sysu.edu.cn/), binding sites for miR-23b-3p were found on annexin A2 (ANXA2). High ANXA2 expression has been reported in PDAC [15]. ANXA2 promotes invasion, metastasis, and epithelial-mesenchymal transition (EMT) in tumors and suppresses apoptosis in PDAC cells [16]. However, the underlying mechanism of miR-23b-3p and its target genes in PDAC remain unclear.

In this study, we explored the role of miR-23b-3p in the progression and metastasis of PDAC. In addition, we found that ANXA2 is a direct target of miR-23b-3p and demonstrated that miR-23b-3p is involved in the regulation of cellular proliferation and migration induced by ANXA2.

\section{Materials and Methods}

Tissue samples

Forty PDAC tissues and 16 adjacent non-tumor tissues were collected from patients with PDAC after surgical resection at the First Affiliated Hospital of Guangxi Medical University, Nanning, China, from January 2010 to January 2013. Informed consent was obtained from the patients before surgery, and this study was approved by the Ethics Committee of Guangxi Medical University. All diagnoses were verified based on pathological evidence.

Cell lines and culture conditions

The PC cell lines Panc-1 and Bxpc-3 were obtained from the Shanghai Cell Bank (Shanghai, China) and maintained according to the supplier's recommendations. Panc-1 cells were cultured in Dulbecco's modified Eagle's medium (Corning, Jiangsu, China), while Bxpc-3 cells were maintained in RPMI 1640 medium with $10 \%$ fetal bovine serum (Sigma), $100 \mu \mathrm{g} / \mathrm{mL}$ streptomycin, and $100 \mu \mathrm{g} / \mathrm{mL}$ penicillin. The cells were grown in a humidified chamber supplemented with $5 \% \mathrm{CO}_{2}$.

\section{Transfection}

The cells were transfected with miR-23b-3p mimic, inhibitor, or corresponding negative controls using RNAiMAX (Invitrogen, CA, USA). Optimum transfection efficiency was obtained with $50 \mathrm{nM}$ mimic (Bxpc-3: 13.26-fold and Panc-1: 15.96-fold) and $100 \mathrm{nM}$ inhibitor (Bxpc-3: 15\% and Panc-1: 2.7\%). 


\section{Cellular Physiology Cell Physiol Biochem 2018;50:823-840 \begin{tabular}{ll|l} 
DOI: 10.1159/000494468 & $\begin{array}{l}\text { O } 2018 \text { The Author(s). Published by S. Karger AG, Basel } \\
\text { www.karger.com/cpb }\end{array}$
\end{tabular} \\ Wei et al.: miR-23b-3p/ANXA2 in PDAC}

RNA isolation and quantitative real-time PCR

Briefly, total RNA was extracted using a Direct-zol RNA Kit (Zymo Research, CA, USA) according to the manufacturer's instructions and used to generate cDNA with a RevertAid Reverse Transcriptase Kit (Thermo Fisher). Subsequently, the expression of mRNA and miRNA was calculated relative to U6 via quantitative real-time PCR (qRT-PCR) on the same samples.

\section{Cell proliferation}

PDAC cell lines were seeded in 96-well plates (5000 cells/well). Then, the cells were transfected with mimic, inhibitor, or negative control and cultured for 24,48 , or $72 \mathrm{~h}$ before measuring cell viability with a Cell Counting Kit-8 (CCK-8) assay (Vazyme, Jiangsu, China) according to the manufacturer's protocol. The medium was removed after adding the CCK-8 reagent to each well, and the cells were incubated at $37^{\circ} \mathrm{C}$ for $1.5 \mathrm{~h}$. Absorbance at $450 \mathrm{~nm}$ was determined using a microplate reader (BioTek, VT, USA). The experiment was performed in triplicate and repeated three times.

\section{Colony formation assay}

Transfected cells were plated in 6-well plates (100 cells/well) and subsequently transfected every 4 days. After 14 days of incubation, the cells were washed three times with phosphate-buffered saline (PBS), fixed with paraformaldehyde, and stained with crystal violet. Colonies of more than 50 cells were counted in 5 random fields under a microscope.

\section{Migration and invasion assays}

Cell migration was detected via wound healing and Transwell assays. For the wound healing assay, the cells were first plated in 6-well plates. The cells were cultured to confluence and transfected with miR$23 \mathrm{~b}-3 \mathrm{p}$ inhibitor or negative control. The cell monolayer was scratched using a 200- $\mu \mathrm{L}$ pipette tip to create a wound. Photographs of the wound were captured with a microscope at 0 and $72 \mathrm{~h}$ from five randomly chosen regions. The area of the wound was measured and analyzed using Image-Pro Plus. The Transwell assay was performed using 24-well Transwell chambers (Corning). The transfected cells were suspended in serum-free medium and seeded in the upper chambers, while $600 \mu \mathrm{L}$ medium containing $10 \%$ fetal bovine serum was added to the lower chambers. After $12 \mathrm{~h}$ incubation, the migrated cells on the lower surface of the membrane were washed gently three times with PBS and stained with crystal violet. From 10 random fields on the membrane, the number of migrated cells was counted under a microscope.

\section{Invasion assay}

For the invasion assay, Matrigel (Corning) was used to pre-coat the membrane surface facing the upper chamber. The following steps were the same as those of the Transwell assay.

\section{Cell cycle assay}

Cell cycle distribution was assayed using a Cell Cycle Kit (Vazyme, Nanjing, China) following the manufacturer's instruction. Approximately $5.0 \times 5.0 \mathrm{r}^{4}$ transfected cells were collected and washed three times with ice-cold PBS. After treatment with RNase A and staining with a propidium iodide solution, the cells were subjected to fluorescence-activated cell sorting analysis.

\section{Apoptosis assay}

For the apoptosis assay, flow cytometry was performed with an Annexin V-PE/7-ADD Staining Kit (Thermo Fisher) according to the manufacturer's instructions. After $72 \mathrm{~h}$ incubation, the transfected cells were collected and washed with PBS and then re-suspended in $200 \mu \mathrm{L}$ of $1 \times$ binding buffer and incubated with $5 \mu \mathrm{L}$ annexin V-PE at room temperature for $10 \mathrm{~min}$. The cells were re-suspended using $200 \mu \mathrm{L}$ of $1 \times$ binding buffer, and $5 \mu \mathrm{L}$ 7-AAD solution was added to the cells. The cells were then incubated on ice before being subjected to flow cytometry within $1 \mathrm{~h}$. 


\section{Cellular Physiology Cell Physiol Biochem 2018;50:823-840

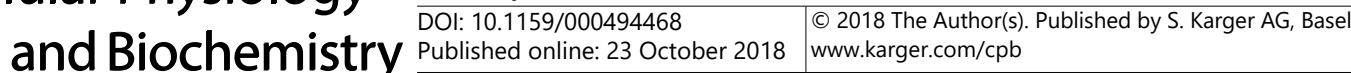 \\ Wei et al.: miR-23b-3p/ANXA2 in PDAC}

\section{Chick chorioallantoic membrane (CAM) assay}

At embryonic day 5, Bxpc-3 cells (approximately $2.0 \times 10^{6}$ ) were inoculated into the chick CAM and incubated at $37^{\circ} \mathrm{C}$ and $70 \%$ humidity. After $24 \mathrm{~h}$, the silicone rings were gently removed from the CAMs. The next day, $2 \mathrm{nmol}$ miR-23b-3p agomir (RiboBio, Guangdong, China) or PBS was injected into the tumor mass. On embryonic day 9, the tumors were collected, measured, and fixed overnight in paraformaldehyde for histology.

\section{Luciferase reporter assay}

Dual-luciferase reporter assays were performed in 96-well plates. HEK293T cells were transfected with ANXA2 3' untranslated region (3'UTR) luciferase reporter plasmids containing wild-type (WT) or mutant (MUT) putative binding sites of miR-23b-3p along with miR-23b-3p-expression or negative control plasmids (GeneChem, Shanghai, China). After $48 \mathrm{~h}$ transfection, luciferase activity was detected using a Dual-Luciferase Reporter Assay Kit (Promega, WI, USA).

\section{Immunohistochemistry}

Tissue samples were fixed with formalin and embedded in paraffin. Sections were prepared for immunohistochemical staining and incubated with a primary antibody against ANXA2 (1:100; Abcam) for $1 \mathrm{~h}$ at $37^{\circ} \mathrm{C}$ and then incubated with a secondary antibody (Long Island, Shanghai, China) for $0.5 \mathrm{~h}$ at $37^{\circ} \mathrm{C}$. The I scale of intensity was scored as : 0 (negative), 1 (weak), 2 (moderate), and 3 (strong) whereas the percentage of positive cells $(\mathrm{P})$ in the area was used: 0, 1 (1-25\%), 2 (26-50\%), 3 (51-75\%) and $4(>75 \%)$. The multiplication of I and P resulted in the total score of $0-12$ [17].

\section{Western blot analysis}

For western blotting, cellular proteins were extracted from Panc-1 cells, separated by SDS-PAGE, and transferred onto a polyvinylidene fluoride membrane. A primary antibody against ANXA2 (1:500; Abcam) was used, and an anti- $\beta$-actin antibody (1:500, Abcam) was used as a control. The intensities of protein bands were analyzed quantitatively using Image-Pro Plus software.

\section{Statistical analysis}

Statistical analyses were performed using SPSS 19.0 (IBM, SPSS, IL, USA). The significance of differences between groups was estimated using the $\chi^{2}$ test or Student's $t$-test. Differences were considered significant at a P-value less than 0.05 .

\section{Results}

Effect of miR-23b-3p on various malignant phenotypes of PC cells

The efficiency of transfection was confirmed by performing qRT-PCR (Fig. 1A). In the CCK-8 array, the growth of Bxpc-3 and Panc-1 PDAC cell lines transfected with miR-

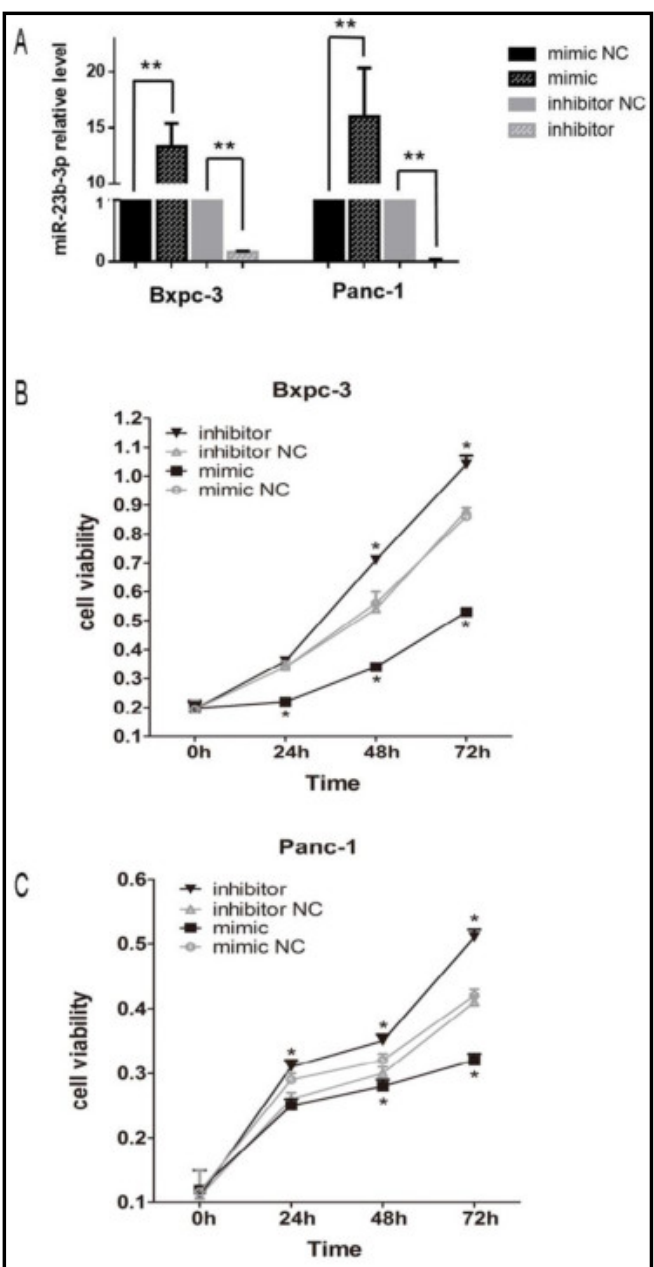

Fig. 1. Influence of miR-23b-3p on cell viability in pancreatic cancer. (A) Relative expression of miR-23b-3p in cells transfected with mimic, mimic negative control (mimic NC), inhibitor, and inhibitor negative control (inhibitor $\mathrm{NC}$ ) $\left({ }^{* *} \mathrm{P}<0.01\right) .(\mathrm{B}, \mathrm{C})$ Cell viability detected using a CCK-8 assay at $0,24,48$, and $72 \mathrm{~h}$ after transfection of Bxpc- 3 and Panc- 1 cells ( $\left.{ }^{*} \mathrm{P}<0.05\right)$. 
Fig. 2. Influence of miR$23 \mathrm{~b}-3 \mathrm{p}$ on colony formation in pancreatic cancer. (A) Colony formation in PDAC Bxpc- 3 and Panc- 1 cells after transfection with miR-23b$3 p$ mimic or inhibitor. (B) Number of colony formation in the experimental groups compared with that in the negative control groups (*P $<0.05$ ).

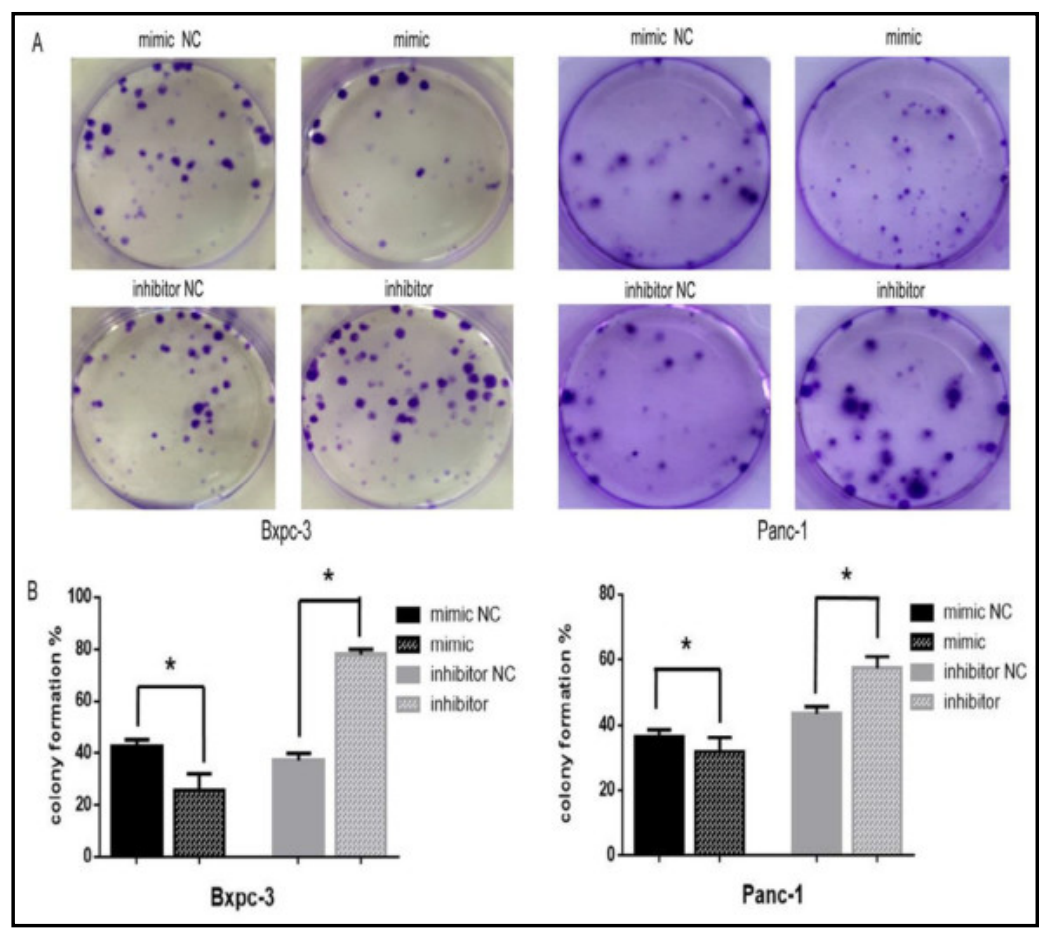

Fig. 3. Influence of miR-23b-3p on cell migration in pancreatic cancer (A) Overexpression or inhibition of miR-23b-3p affects the migration of Bxpc-3 and Panc- 1 cells as seen using a wound healing assay at 0 and $72 \mathrm{~h}$. (B) Migration area of the two cell lines after transfection $\left({ }^{*} \mathrm{P}<0.05\right)$.

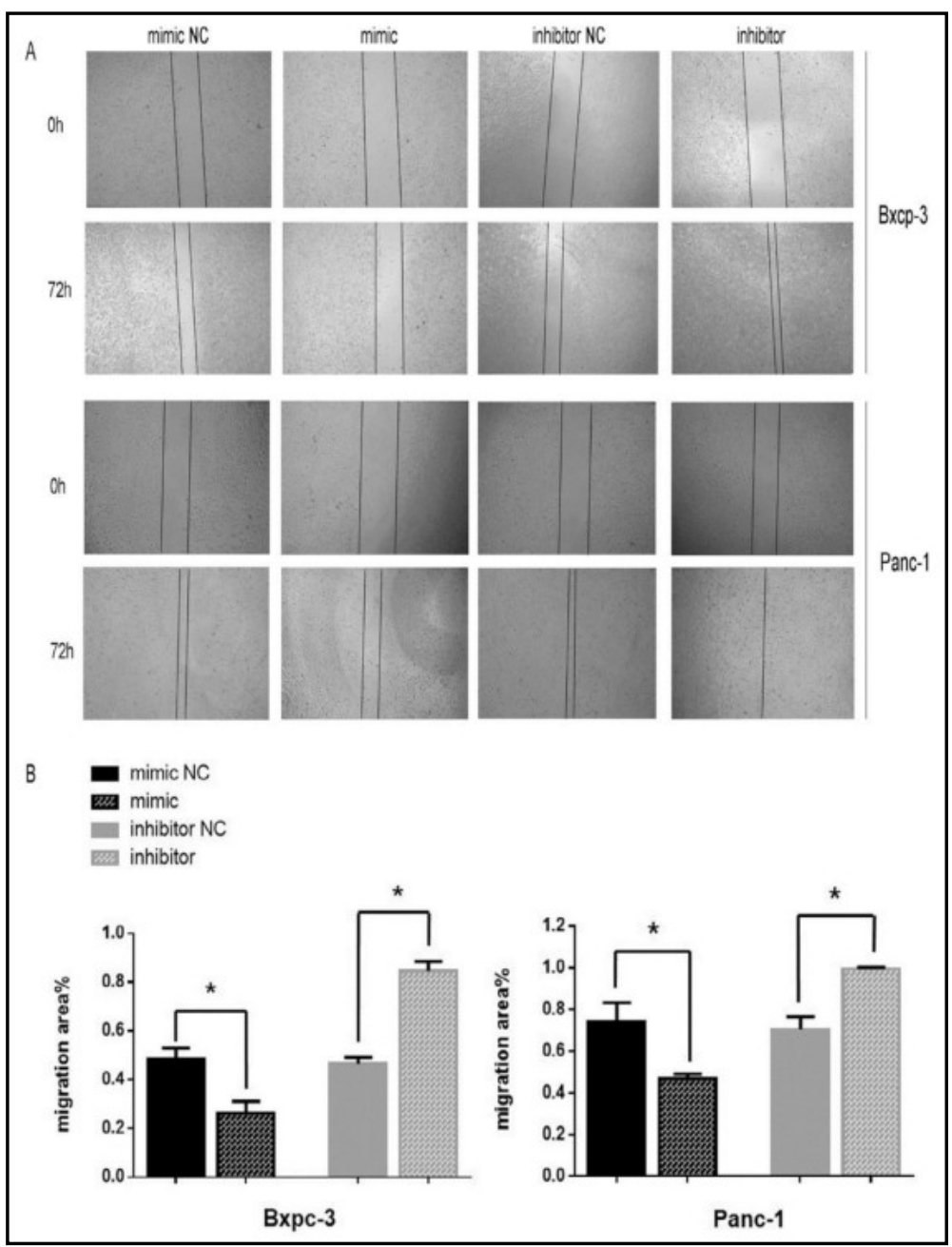


Fig. 4. Influence of miR-23b-3p on cell invasion in pancreatic cancer. (A) Migratory ability of Bxpc-3 and Panc-1 cells after transfection with miR-23b-3p mimic or inhibitor as detected by Transwell assay. (B) Number of migrated Bxpc-3 and Panc-1 cells in the experimental groups compared with that in the negative control groups $\quad\left({ }^{*} \mathrm{P}<0.05\right.$, $* * \mathrm{P}<0.01)$. Invasive ability of Bxpc-3 and Panc-1 cells after transfection with mimic or inhibitor as detected by Matrigel Transwell assay. (D) Number of invaded Bxpc-3 and Panc- 1 cells in the experimental groups compared with that in the negative control groups $\quad\left({ }^{*} \mathrm{P}<0.05\right.$, $* * \mathrm{P}<0.01$ ).
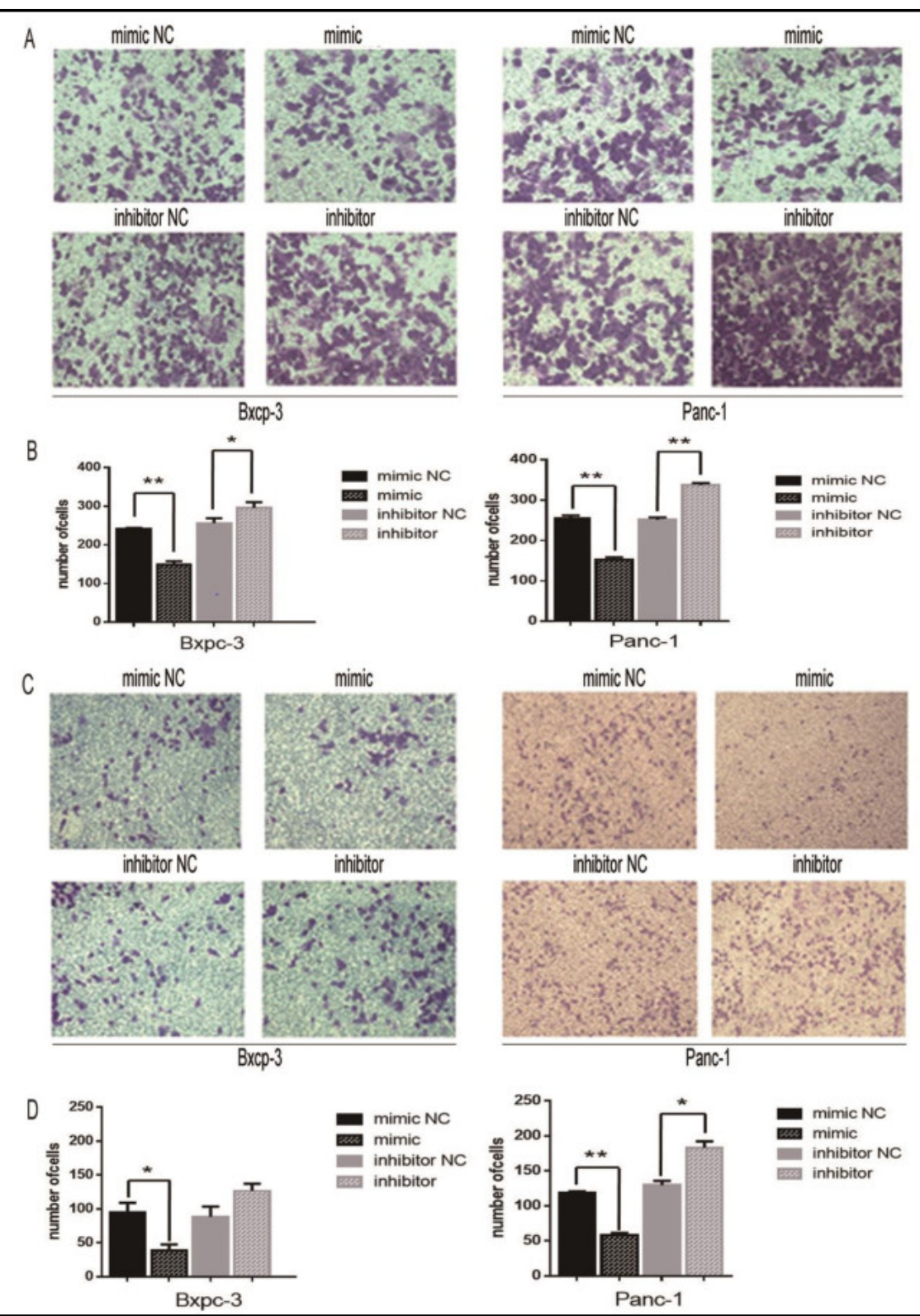

$23 b-3 p$ mimic was significantly reduced after transfection, whereas miR-23b-3p inhibitor transfection induced an increase in cell number compared with the negative control (Fig. 1B, 1C). The plate-based colony formation assay further demonstrated that the colonyforming ability of PDAC cells was significantly suppressed after miR-23b-3p overexpression (Fig. 2). We observed that transfection of miR-23b-3p mimic indeed retarded the ability of cells to migrate and fill the wound, as compared with the negative control (Fig. 3). In the migration and Matrigel invasion assays, the number of miR-23b-3p mimic-transfected cells that penetrated through the membrane was clearly lower than that of cells transfected with control (Fig. 4). Flow cytometry indicated that miR-23b-3p overexpression in PDAC cells resulted in G0/G1 arrest, a reduction in the $S$ phase population (Fig. 5), and the promotion of apoptosis (Fig. 6). The in vivo CAM experiments showed that upregulating miR-23b-3p expression could inhibit tumor formation (Fig. 7). 
Fig. 5. Detection of cell cycle distribution using flow cytometry in transfection with miR-23b-3p mimic or inhibitor (A) Cell cycle distribution of Bxpc-3 and Panc-1 cells detected via flow cytometry after transfection with miR-23b-3p mimic and inhibitor. (B) Cell cycle distribution of the two cell lines after transfection $\left({ }^{*} \mathrm{P}<0.05\right)$. PDAC cells after

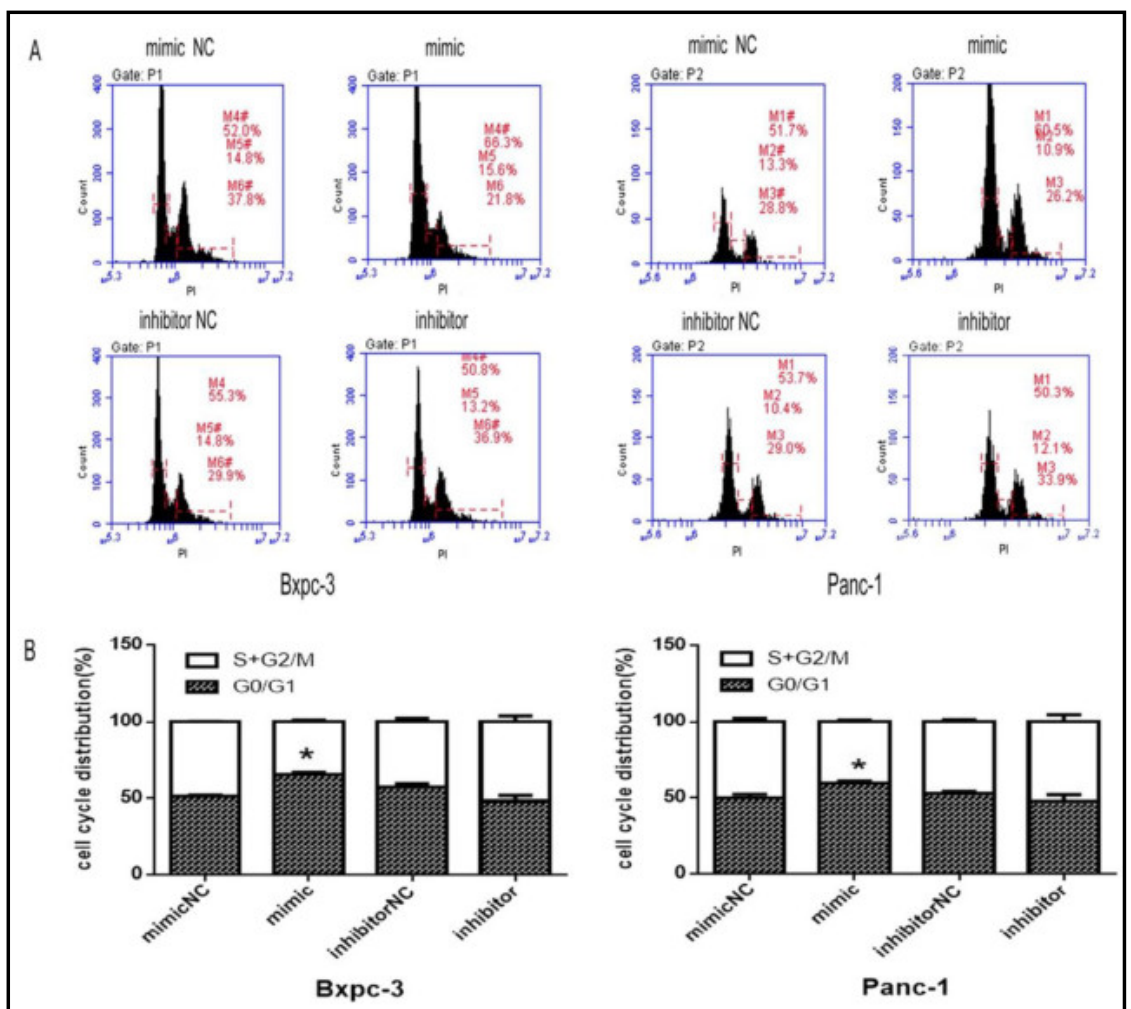

Fig. 6. Influence of miR-23b-3p on apoptosis in pancreatic cancer. (A) Apoptosis in Bxpc-3 and Panc-1 cells after transfection with miR-23b$3 p$ mimic or inhibitor, as determined by flow cytometry. (B) Apoptosis rate of Bxpc3 and Panc1 cells in the experimental $\begin{array}{llllll}g & r & o & u & p & s\end{array}$ compared with that in the negative control groups.

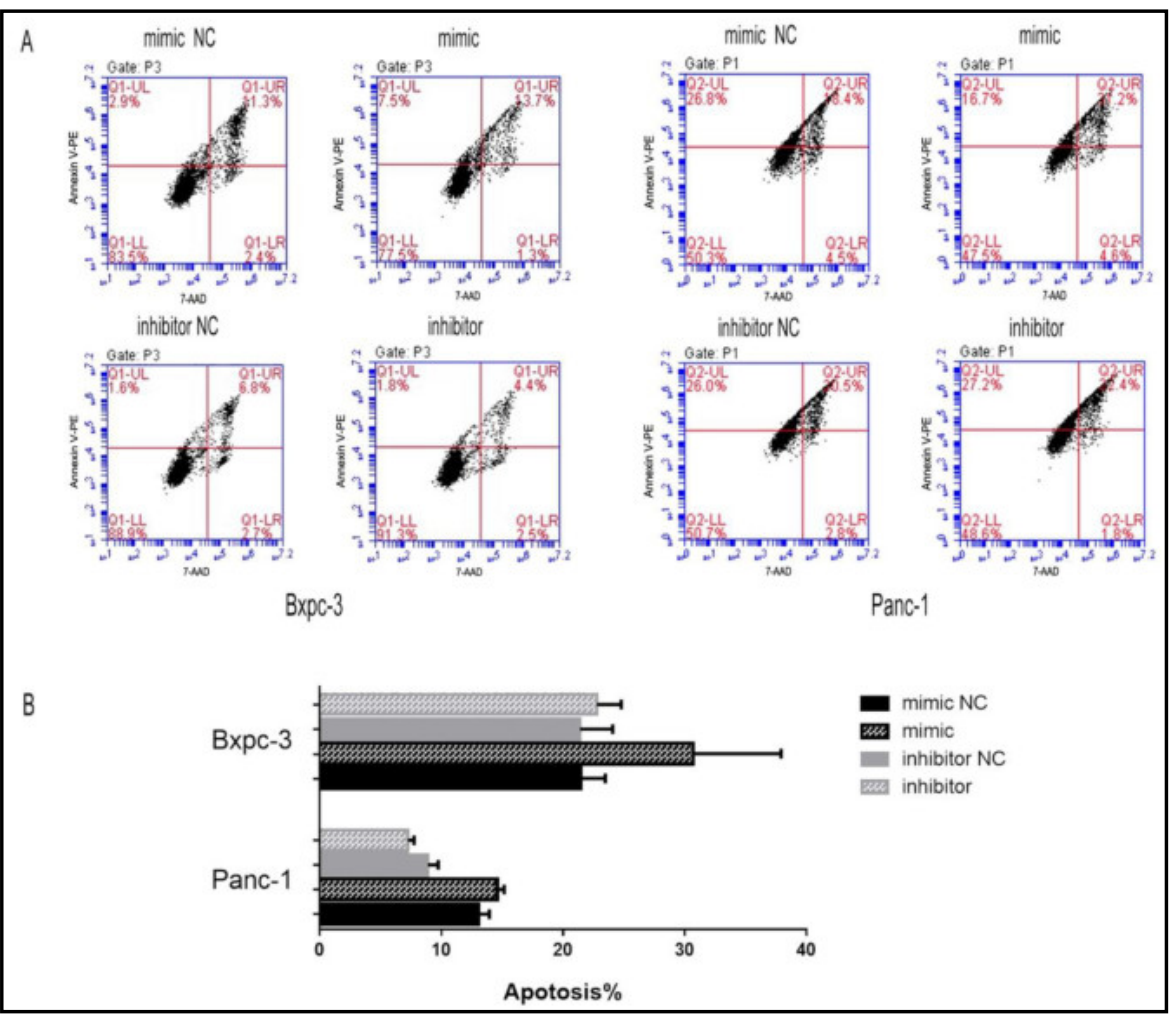




\section{Cellular Physiology Cell Physiol Biochem 2018;50:823-840 \begin{tabular}{ll|l} 
DOl: 10.1159/000494468 & $\begin{array}{l}\text { O 2018 The Author(s). Published by S. Karger AG, Basel } \\
\text { www.karger.com/cpb }\end{array}$ \\
\cline { 2 - 3 }
\end{tabular}

Fig. 7. Influence of miR-23b-3p on tumor formation in pancreatic cancer. (A) Tumor formation by Bxpc-3 cells in CAMs after injection with miR-23b$3 p$ agomir negative control (NC), PBS, and miR-23b-3p agomir. (B) Tumor size in CAMs with Bxpc-3 cells after the cells were injected with miR-23b$3 p$ agomir NC, PBS, or miR-23b-3p agomir $\left({ }^{*} \mathrm{P}<0.05\right)$. (C) Histological staining of the tumors generated by Bxpc-3 cells in CAMs after injection with miR-23b-3p agomir compared with the agomir control group (NC) and PBS $(100 \times, 200 \times)$.

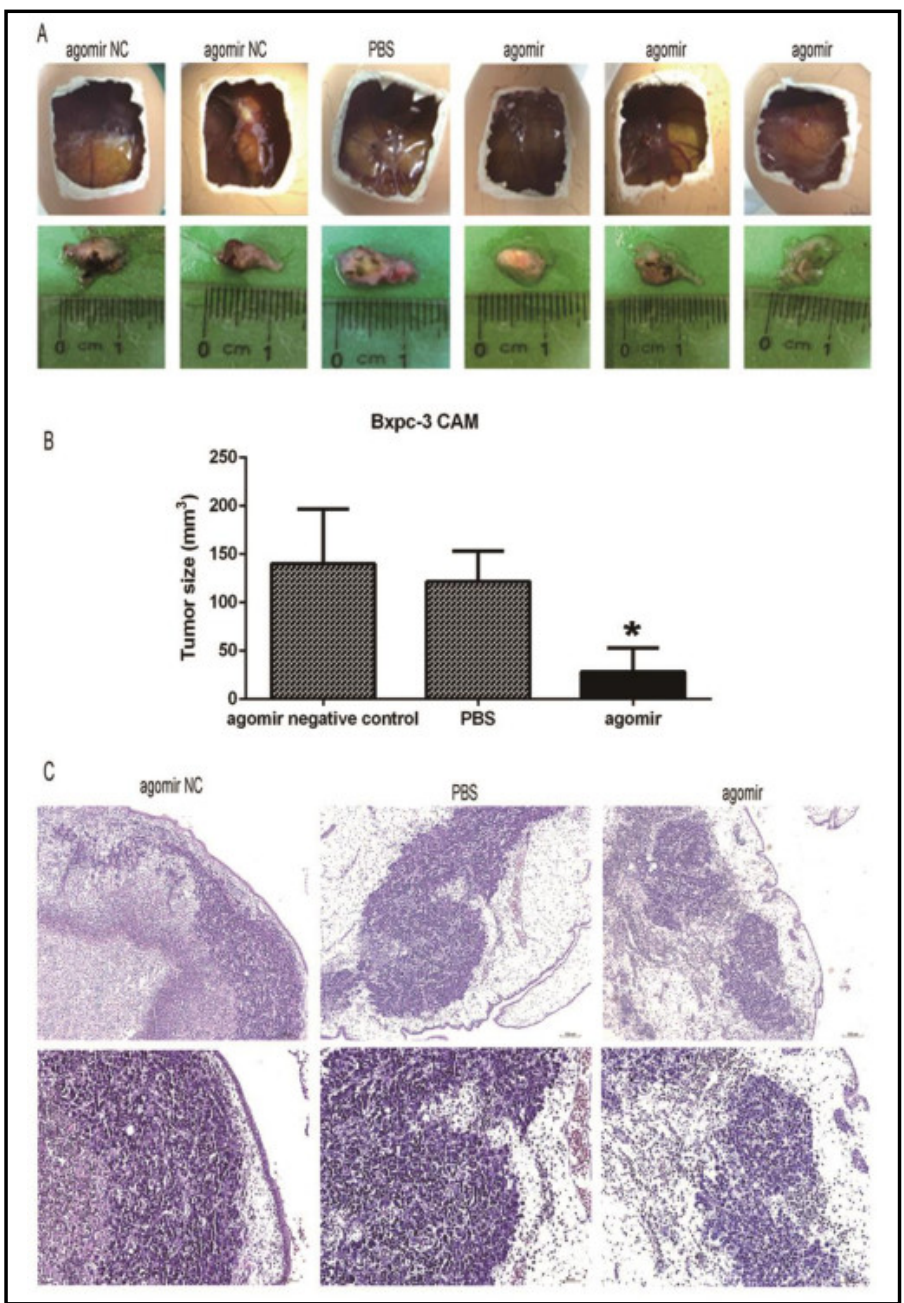

ANXA2 is a direct target of miR-23b-3p in PC

Binding between miR-23b-3p and ANXA2 was confirmed using several online prediction platforms, including starBase V 2.0. (Fig. 8A, 8B). Thus, ANXA2 is a potential target of miR$23 b-3 p$. We further observed a negative correlation between miR-23b-3p and ANXA2 expression in four cancer datasets via bioinformatics analysis including Gene Expression Omnibus (GEO) (Fig. 8C, 9). More importantly. The dual-luciferase gene reporter assay revealed that the relative luciferase activity of ANXA2-3'UTR-WT was reduced after miR$23 b-3 p$ overexpression, whereas the luciferase activity of ANXA2-3'UTR-MUT remained unchanged. These results confirmed that miR-23b-3p could specifically bind to the $3^{\prime} U T R$ of ANXA2, and qRT-PCR further validated the relationship between miR-23b-3p and ANXA2 in vitro (Fig. 10). Next, we examined the expression of ANXA2 in several human cancers including PC through The Cancer Genome Atlas (TCGA) (Fig. 11), and then verified ANXA2 expression in PDAC tissues using immunohistochemistry (Fig. 12A). ANXA2 expression was significantly higher in PDAC tissues than in adjacent pancreatic tissues $(\mathrm{P}<0.05)$ (Table 1$)$. Clinically, ANXA2 expression was related to the following: tumor size $(r=0.379, P=0.024)$; tumor, node, and metastasis (TNM) stage $(r=0.401, P=0.021)$; neural invasion $(r=0.36$, $\mathrm{P}=0.042)$; and survival duration $(\mathrm{r}=-0.36, \mathrm{P}=0.042)$. Meanwhile, Spearman's correlation indicated that miR-23b-3p expression in PDAC was significantly negatively correlated with the immunohistochemistry scores of ANXA2 $(\mathrm{r}=-0.402, \mathrm{P}=0.010)$ (Table 2$)$. The expression level of ANXA2 was examined after transfection of PDAC cells with miR-23b-3p mimic. Reduced ANXA2 expression was observed following miR-23b-3p mimic transfection compared with 
Fig. 8. Relationship between miR-23b-3p and ANXA2. (A) Negative correlation between the expression of miR-23b$3 p$ and its target genes using starBase V 2.0 (B) Binding site of miR-23b$3 p$ on ANXA2 mRNA. (C) ANXA2 analyzed using GEO datasets.

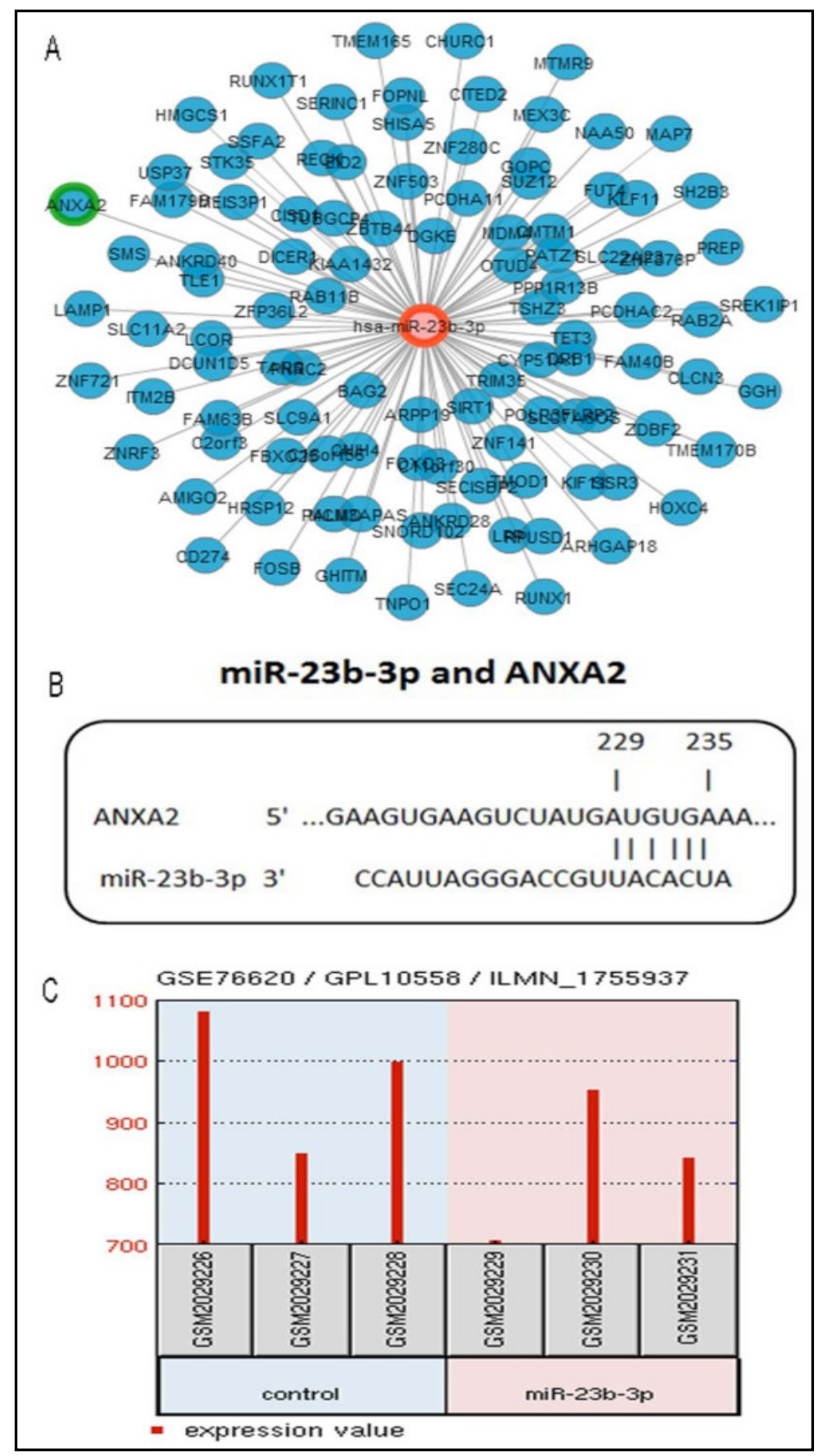

negative control transfection (Fig. 12B, 12C). In addition, miR-23b-3p overexpression tended to inhibit ANXA2 protein expression. Moreover, ANXA2 protein expression was upregulated after miR-23b-3p was inhibited (Fig. 12D). However, transfection of PDAC cells with miR$23 b-3 p$ mimic or inhibitor failed to induce significant changes in the expression of zinc finger E-box-binding homeobox 1 (ZEB1) protein. 


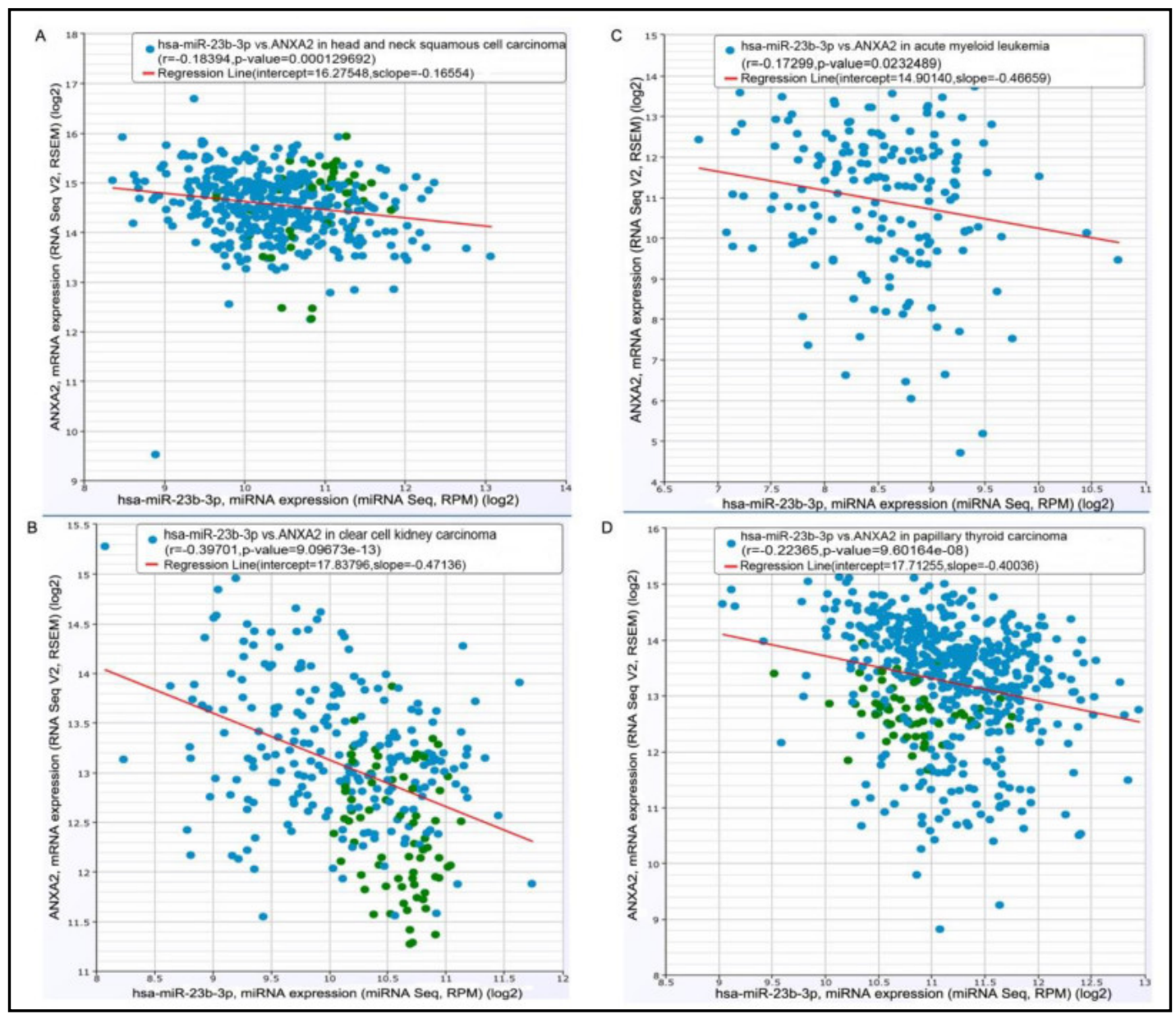

Fig. 9. Correlation between miR-23b-3p with ANXA2 based on starBase data. Negative correlation between miR-23b-3p with ANXA2 expression in head and neck squamous cell carcinoma (A), clear cell kidney carcinoma (B), acute myeloid leukemia (C), and papillary thyroid carcinoma (D), identified using the starBase V 2.0 Pan-cancer analysis project $(\mathrm{P}<0.05)$.

Fig. 10. Correlation between miR23b-3p with ANXA2 based on a dual-luciferase reporter assay. Relative luciferase activity in cells cotransfected with ANXA2-3'UTR-NC, ANXA2-3'UTR-WT, or ANXA2-3'UTRMUT and miRNA negative control or miR-23b-3p mimic $\left({ }^{*} \mathrm{P}<0.05\right)$.

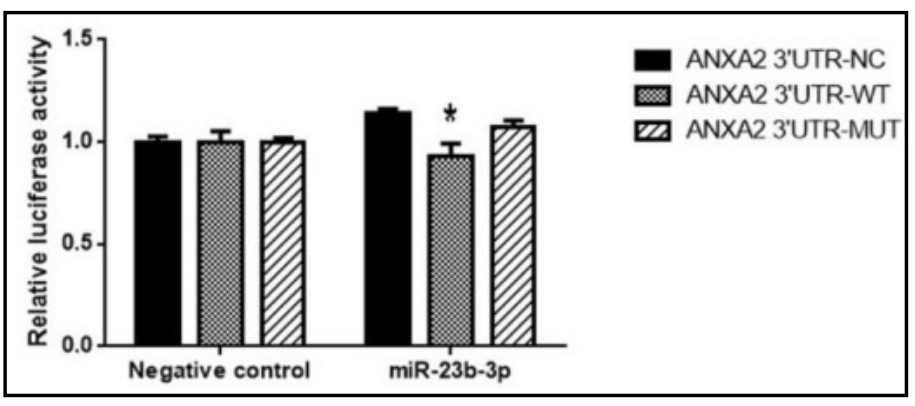




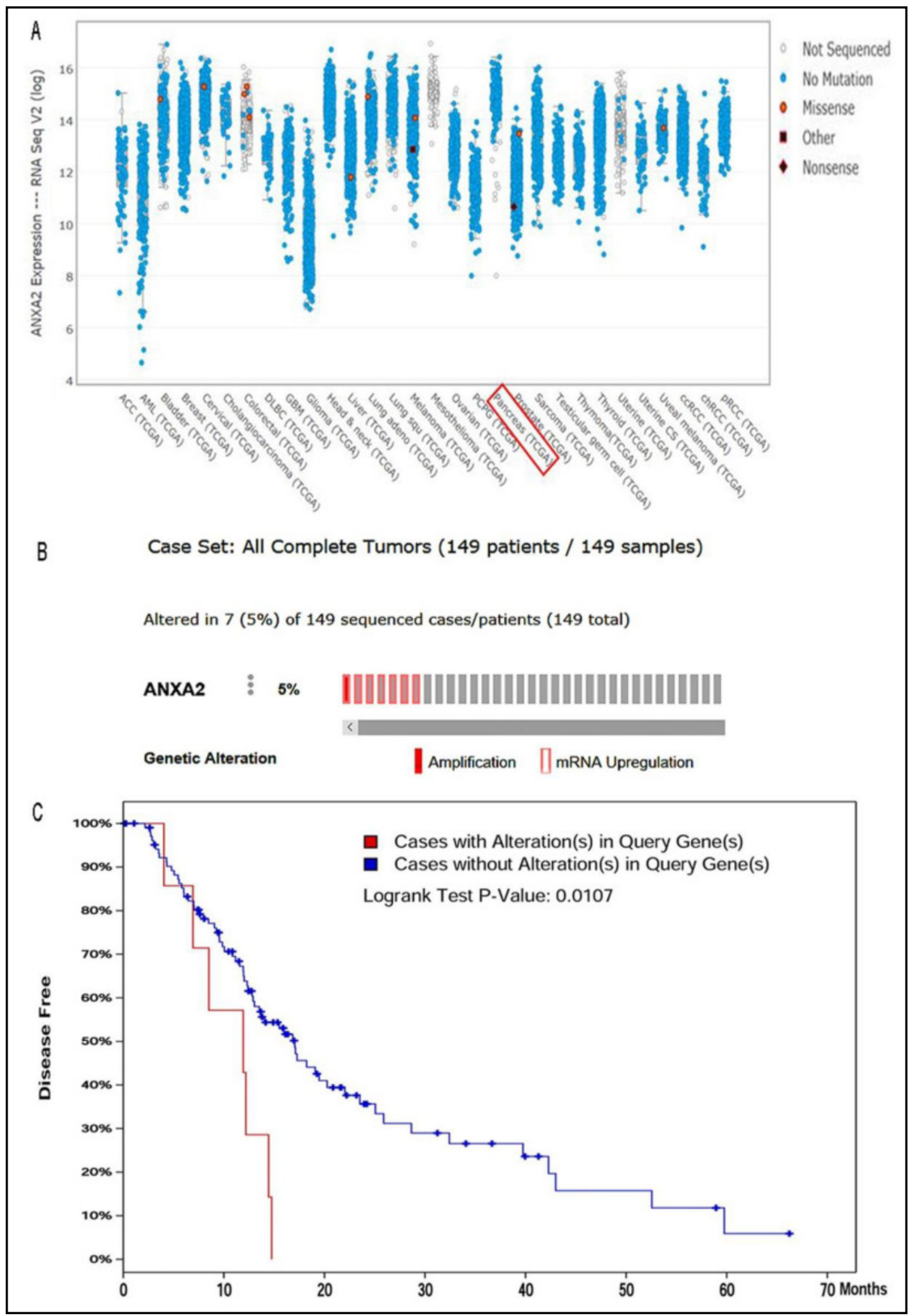

Fig. 11. Genetic alteration of ANXA2 in PDAC. (A) ANXA2 expression in human cancers as analyzed by TCGA. (B) Amplification and transcriptional upregulation of ANXA2 detected in 5\% of PDAC cases via cBioPortal analysis. (C) Disease-free survival of patients with ANXA2 amplification and transcriptional upregulation is shorter than that of patients without these alterations. $(\mathrm{P}<0.05)$. 


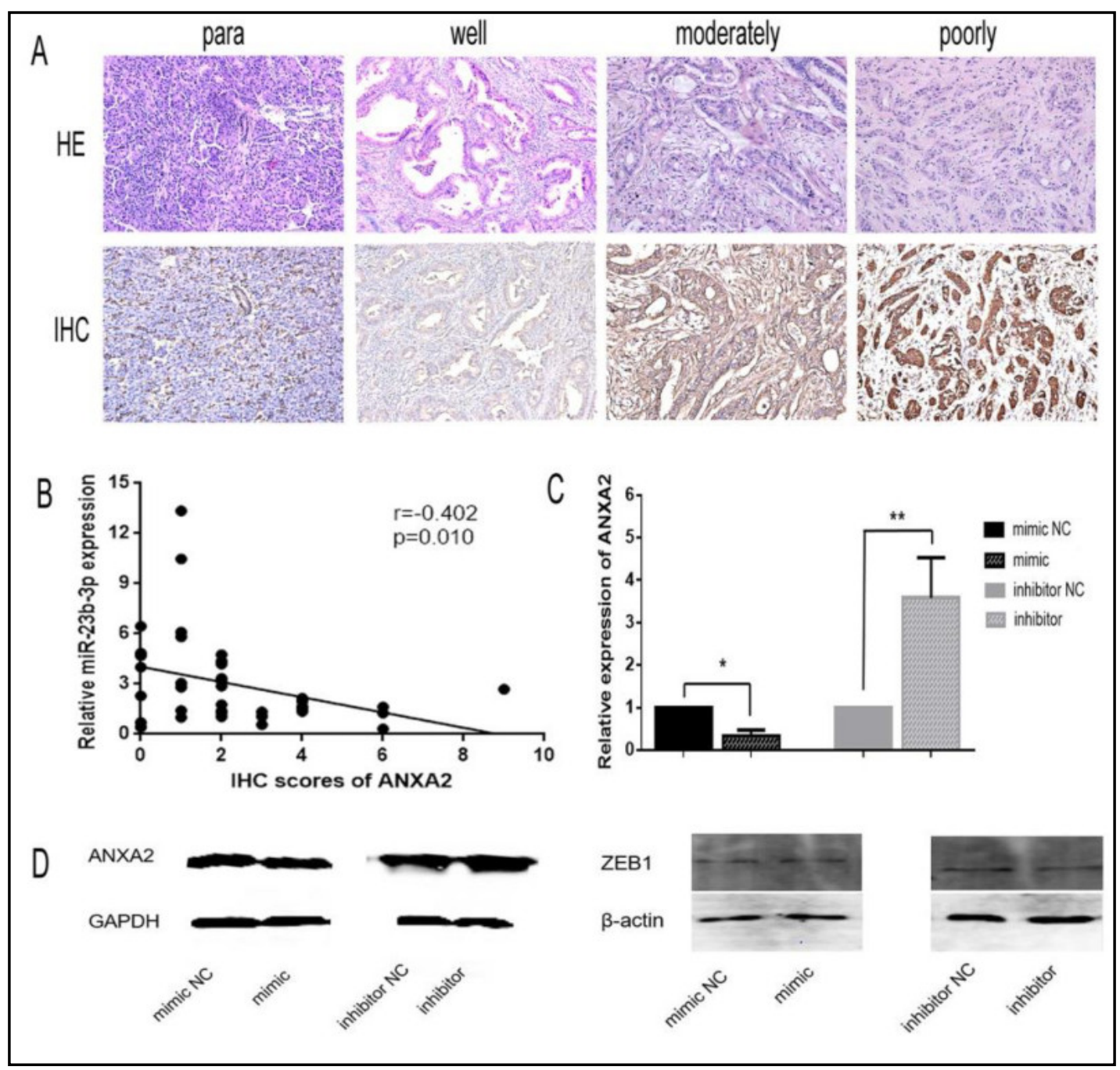

Fig. 12. Correlation between miR-23b-3p and immunohistochemistry (IHC) scores of ANXA2 based on IHC and western blot analyses. (A) ANXA2 protein expression detected via IHC in PDAC para-cancer tissues, welldifferentiated PDAC tissues, moderately differentiated PDAC tissues, and poorly differentiated PDAC tissues. ANXA2 protein located in the cytoplasm of pancreatic cells and PC cells. Top: hematoxylin and eosin-stained sections; bottom: IHC-stained sections $(200 \times)$. (B) Correlation between the expression of miR-23b-3p and IHC scores of ANXA2. (C) Relative expression of ANXA2 mRNA after transfection of cells with miR-23b-3p mimic, mimic negative control (mimic NC), inhibitor, or inhibitor negative control (inhibitor $\mathrm{NC})\left({ }^{*} \mathrm{P}<0.05\right.$, $\left.{ }^{* *} \mathrm{P}<0.01\right)$. (D) Relative protein expression of ANXA2 and ZEB1 after transfection of cells with miR-23b-3p mimic, mimic negative control (mimic NC), inhibitor, or inhibitor negative control (inhibitor NC).

Table 1. Expression of ANXA2 in different pancreatic tissues

\begin{tabular}{lccccc}
\hline & Total & Negative (\%) & Positive (\%) & $\chi^{2}$ value & P-value \\
\hline Para-cancer tissue & 16 & $11(68.5)$ & $5(31.5)$ & & \\
PDAC tissue & 40 & $15(37.5)$ & $25(62.5)$ & 4.487 & 0.034 \\
\hline
\end{tabular}




\section{Discussion}

It has been demonstrated that miR-23b-3p is expressed at low levels in a variety of malignant tumors, including liver cancer [18], bladder cancer [19], cervical cancer [20], colorectal cancer [21], and prostate cancer [22]. Our preliminary experiments showed that PDAC tissues and cell lines also expressed low levels of miR-23b-3p. The expression of miR-23b$3 p$ was examined in paraffinembedded pancreatic tissues, and it was found to be significantly lower in 57 PDAC tissue specimens than in 25 precancerous pancreatic tissue specimens. The low miR-23b-3p expression group experienced larger tumor volumes and deeper tumor infiltration compared with the high miR$23 b-3 p$ expression group. In addition, low miR-23b-3p expression was positively correlated with tumor stages III-IV. Compared with the high miR-23b-3p expression group, the low miR-23b-3p expression group had a poorer prognosis. Multivariate analysis showed that miR-23b-3p could serve as an independent prognostic factor for patients with PDAC [14].

Studies have shown that miR-23b-3p has some impact on tumor biological behavior. MiR-23b-3p overexpression inhibits the proliferative capability of breast cancer cells [23, 24], ovarian cancer cells [25], hepatocarcinoma cells [18], colorectal cancer cells [21], and endometrial cancer cells [26]. However, a study conducted by Wang et al. yielded inconsistent results [27]. In their study, two PDAC cell lines, Bxpc-3 and Panc-1, were transiently transfected with miR-23b-3p mimics or inhibitors and then subjected to CCK-8 and colony formation assays. These alterations in miR-23b-3p expression failed to affect significantly the proliferative capacity of PDAC cells. Consistent with the findings of previous reports showing that miR-23b-3p inhibits tumor cell proliferation, the results of the present study indicate that miR-23b-3p also suppresses the proliferative capability of PDAC cells; however, these results are inconsistent with the findings of Wang et al. [27]. The underlying reason for this disparity may be the different experimental environments and methods. For example, the plate-based colony formation assay was performed differently. In the study conducted by Wang et al., the culture medium was not replaced, and small interfering RNA (siRNA) transfection was not repeated within 14 days after transient transfection with miR-23b$3 p$ siRNA. In the present study, the culture medium was changed, and miR-23b-3p siRNA transfection was repeated every $96 \mathrm{~h}$ until 14 days after the initial transient transfection with miR-23b-3p siRNA. Therefore, to clarify further the inhibitory effect of miR-23b-3p

Table 2. Relationship between ANXA2 expression and the clinical characteristics of patients with PDAC, $\chi^{2}$ test, ${ }^{*} \mathrm{P}<0.05$

\begin{tabular}{|c|c|c|c|c|c|}
\hline & Total & Negative (\%) & Positive (\%) & $\chi^{2}$ value & $\mathrm{P}$-value \\
\hline Sex & 40 & & & & 0.336 \\
\hline Male & 23 & $7(30.4)$ & $16(69.6)$ & 1.153 & \\
\hline Female & 17 & $8(47.1)$ & $9(52.9)$ & & \\
\hline Age (years) & 40 & & & & 1.000 \\
\hline$\leq 56$ & 22 & $8(36.4)$ & $14(63.6)$ & 0.027 & \\
\hline$>56$ & 18 & 7 (38.9) & $11(61.1)$ & & \\
\hline Lifetime (months) & 40 & & & & $0.042^{*}$ \\
\hline$\leq 12$ & 25 & $6(24.0)$ & $19(76.0)$ & 5.184 & \\
\hline$>12$ & 15 & $9(60.0)$ & $6(40.0)$ & & \\
\hline Differentiation grade & 40 & & & & 0.488 \\
\hline Well & 7 & $2(28.6)$ & $5(71.4)$ & 1.713 & \\
\hline Moderate & 24 & $11(45.8)$ & $13(54.2)$ & & \\
\hline Poor & 9 & $2(22.2)$ & $7(77.8)$ & & \\
\hline Neural invasion & 40 & & & 5.184 & $0.042^{*}$ \\
\hline$(-)$ & 15 & $9(60.0)$ & $6(40.0)$ & & \\
\hline$(+)$ & 25 & $6(24.0)$ & $19(76.0)$ & & \\
\hline Position & 40 & & & 0.000 & 1.000 \\
\hline Pancreatic head & 32 & $12(37.5)$ & $20(62.5)$ & & \\
\hline Pancreatic body/tail & 8 & $3(37.5)$ & $5(62.5)$ & & \\
\hline Size $(\mathrm{cm})$ & 40 & & & 5.736 & $0.024^{*}$ \\
\hline$\leq 3$ & 17 & $10(58.8)$ & $7(41.2)$ & & \\
\hline$>3$ & 23 & $5(21.7)$ & $18(78.3)$ & & \\
\hline CA199 (U/mL) & 40 & & & 0.000 & 1.000 \\
\hline$\leq 37$ & 8 & $3(11.1)$ & $5(88.9)$ & & \\
\hline$>37$ & 32 & $12(42.5)$ & $20(57.5)$ & & \\
\hline CEA (ng/mL) & 40 & & & 1.778 & 0.318 \\
\hline$\leq 55$ & 24 & $11(45.8)$ & $13(54.2)$ & & \\
\hline$>55$ & 16 & $4(25.0)$ & $12(75.0)$ & & \\
\hline TNM & 40 & & & 6.423 & $0.021 *$ \\
\hline $1-2$ & 19 & $11(57.9)$ & $8(42.1)$ & & \\
\hline $3-4$ & 21 & $4(19.0)$ & $17(81.0)$ & & \\
\hline T stage & 40 & & & 0.000 & 1.000 \\
\hline $\mathrm{T} 1-\mathrm{T} 2$ & 4 & $1(44.9)$ & $3(55.1)$ & & \\
\hline T3-T4 & 36 & $14(36.4)$ & $22(63.6)$ & & \\
\hline $\mathrm{N}$ stage & 40 & & & 0.007 & 1.000 \\
\hline No & 21 & $8(38.1)$ & $13(61.9)$ & & \\
\hline $\mathrm{N} 1$ & 19 & $7(36.8)$ & $12(63.2)$ & & \\
\hline M stage & 40 & & & 0.289 & 0.691 \\
\hline M0 & 33 & $13(39.4)$ & $20(60.6)$ & & \\
\hline M1 & 7 & $2(28.6)$ & $5(71.4)$ & & \\
\hline
\end{tabular}


on the proliferative capability of PDAC cells, other PDAC cell lines should be examined and additional experimental approaches should be employed in future studies.

MiR-23b-3p overexpression reportedly inhibits the invasion of gastric cancer cells [28], bladder cancer cells [29], prostate cancer cells [30], tongue cancer cells [31], liver cancer cells [32], and colorectal cancer cells [21]. The present study yielded similar results. The scratch assay showed that miR-23b-3p attenuated the planar migratory potential of Bxpc-3 and Panc-1 PDAC cells, which was further confirmed by the results of Transwell experiments. In contrast, inhibition of miR-23b-3p led to an enhancement of the invasive capability of Panc- 1 cells. The ability of Bxpc-3 cells to invade through Matrigel was somewhat increased after the inhibition of miR-23b-3p; however, the increase was not statistically significant. This insignificant increase may be related to the intrinsic invasive ability of Bxpc-3 cells.

MiR-23b-3p is capable of inducing apoptosis in colorectal cancer cells [5], prostate cancer cells [33], and cervical cancer cells [34]. The percentage of apoptotic PDAC cells was somewhat increased after miR-23b-3p overexpression; however, the difference was not statistically significant. It is likely that miR-23b-3p exerts distinct effects on apoptosis in different tumors and different cell lines. To clarify the effect of miR-23b-3p on the apoptosis of PDAC cells, other PDAC cell lines must be examined and additional apoptosis detection methods should be employed.

In a nude mouse model of tumorigenesis, miR-23b-3p overexpression inhibited the growth of endometrial cancer xenografts [33]. In the present study, a chicken embryo CAM assay to examine the tumorigenesis of Bxpc-3 cells showed that miR-23b-3p overexpression significantly limited the size of tumors or even prevented tumor formation. Taken together, all of the above results indicate that miR-23b-3p suppresses the proliferative capability and metastatic potential of PDAC cells.

The mechanisms by which miR-23b-3p participates in tumor development and progression have been reported. MiR-23b-3p affects the expression of vascular endothelial growth factor indirectly by regulating frizzled-7 and mitogen-activated protein kinase kinase kinase 1, thereby inhibiting angiogenesis in colon cancer [21]. In addition, miR-23b-3p inhibits the proliferation and EMT of gastric cancer cells by regulating the Notch2 pathway and Ets1 gene [35]. Proline-rich tyrosine kinase 2 (Pyk2) is an important factor in EMT [36]. MiR-23b-3p regulates Pyk2 via its $3^{\prime} \mathrm{UTR}$, thereby affecting the migration and invasion of hepatocarcinoma cells [18]. MiR-23b-3p binds to the 3'UTR of a number of cytoskeletal genes, such as LIM domain kinase 2, Rho guanine nucleotide exchange factor 6 , cofilin 2 , phosphoinositide 3-kinase regulatory subunit 3, and urokinase-plasminogen activator. Inhibition of miR-23b-3p expression activates cytoskeletal remodeling pathways, resulting in the enhancement of the migratory and invasive capabilities of breast cancer cells [24]. The overexpression of miR-23b-3p downregulates the expression of metastasis-associated in colon cancer-1, leading to cell cycle arrest at the G1 phase and inhibition of the proliferation, migration, and invasion of endometrial cancer cells [37]. MiR-23b-3p regulates autophagy in PDAC by inhibiting autophagy-related protein 12 , thereby enhancing the sensitivity of PDAC cells to radiotherapy [27]. MiR-23b-3p inhibits the development and progression of tumors through distinct mechanisms; however, its effects on the biological functions of PDAC and the underlying mechanisms have not been reported.

Bioinformatic analysis predicted that the ANXA2 gene contains binding sites for miR23b-3p. As a member of the annexin family, ANXA2 has been shown to play important roles in the development and progression of a variety of tumors. ANXA2 binds to tissue plasminogen activator, which promotes the conversion of plasminogen into plasmin, degradation of the extracellular matrix and the invasion of breast cancer cells [38]. Zheng et al. showed that ANXA2 is transported from the cytoplasm of PDAC cells to the cell surface after tyrosine 23 phosphorylation. ANXA2 and transforming growth factor beta (TGF- $\beta$ ) then act together to induce EMT in PDAC cells, thereby promoting PDAC cell metastasis [36]. In addition, they found that semaphorin 3D (Sema3D) is responsible for directing axonal extension during neuron growth and development. ANXA2 promotes the secretion of Sema3D by PDAC cells, which may promote the infiltration of PDAC cells through neural invasion [15]. 


\section{Cellular Physiology Cell Physiol Biochem 2018;50:823-840 \begin{tabular}{l|l|l} 
and Biochemistry Published online: 23 October 2018 & $\begin{array}{l}\text { ○ 2018 The Author(s). Published by S. Karger AG, Basel } \\
\text { www.karger.com/cpb }\end{array}$ \\
\hline
\end{tabular}}

Using a bioinformatics approach, we found a negative correlation between miR-23b$3 p$ and ANXA2 expression in a variety of malignant tumors. This indicates that miR-23b$3 p$ may regulate ANXA2 in a variety of tumors. The results demonstrate that miR-23b-3p binds specifically to the $3^{\prime}$ UTR of ANXA2 and inhibits the expression of ANXA2 mRNA. In addition, although ANXA2 protein expression showed no significant differences between the groups, it tended to be inhibited following miR-23b-3p overexpression. Moreover, ANXA2 protein expression was upregulated following miR-23b-3p inhibition. It may therefore be necessary to optimize the experimental conditions and identify the optimum antibody titer and incubation time to detect a significant effect.

The present study also explored the potential clinical value of ANXA2 using specimens from patients. The results showed that ANXA2 was expressed at a higher level in PDAC compared with the control group. Moreover, high ANXA2 expression was positively correlated with large tumor volume, advanced TNM stage, and shorter survival time. The results indicate that high ANXA2 expression promotes PDAC proliferation and accelerates disease progression, resulting in poor prognosis and survival. In addition, high ANXA2 expression was positively correlated with tumor nerve invasion, indicating that ANXA2 promotes nerve invasion in PDAC. The above finding is consistent with the results of Zheng et al. [15]. Spearman's correlation analysis revealed a negative correlation between miR$23 b-3 p$ expression and ANXA2 protein expression. These results indicated that reciprocal negative regulation exists between miR-23b-3p and ANXA2 in PDAC tissues.

ZEB1 is a zinc finger transcription factor with an important role in TGF- $\beta$-induced EMT [36]. In PDAC, TGF- $\beta$ signaling promotes EMT by inducing the expression of transcription factors, such as SNAIL/SLUG and ZEB1/ZEB2. ZEB1, ZEB2, and other transcription factors inhibit the expression of the epithelial cell adhesion protein E-cadherin. As a result, the adhesion between cells becomes weakened, and tumor cells can migrate and invade more readily [37]. In endometrial cancer, miR-23b-3p has been confirmed to participate in the occurrence of EMT. MiR-23b-3p is expressed at a low level in epithelial tissues and acts as an inhibitory factor of EMT [33]. In cervical cancer and bladder cancer, miR-23b-3p overexpression inhibits the expression of ZEB1 mRNA $[38,39]$. In the present study, miR$23 \mathrm{~b}-3 \mathrm{p}$ overexpression failed to induce significant changes in ZEB1 protein levels. Due to the large molecular weight of ZEB1 protein, it might be necessary to optimize the conditions of western blot analysis, such as increasing the antibody incubation time and adjusting the antibody concentration, to detect a significant effect. It is unlikely that miR-23b-3p affects the expression of ZEB1 protein in PDAC directly through post-transcriptional regulation.

\section{Conclusion}

The

results of the dualluciferase reporter, qRTPCR, western blot, and immunohistochemical analyses demonstrate that ANXA2 is a target gene of miR-23b-3p. MiR-23b$3 p$ binds to the $3^{\prime} \mathrm{UTR}$ of ANXA2 mRNA, induces the degradation of ANXA2 mRNA, and inhibits the expression of ANXA2 protein, thereby affecting the malignant progression of PDAC (Fig. 13). ANXA2

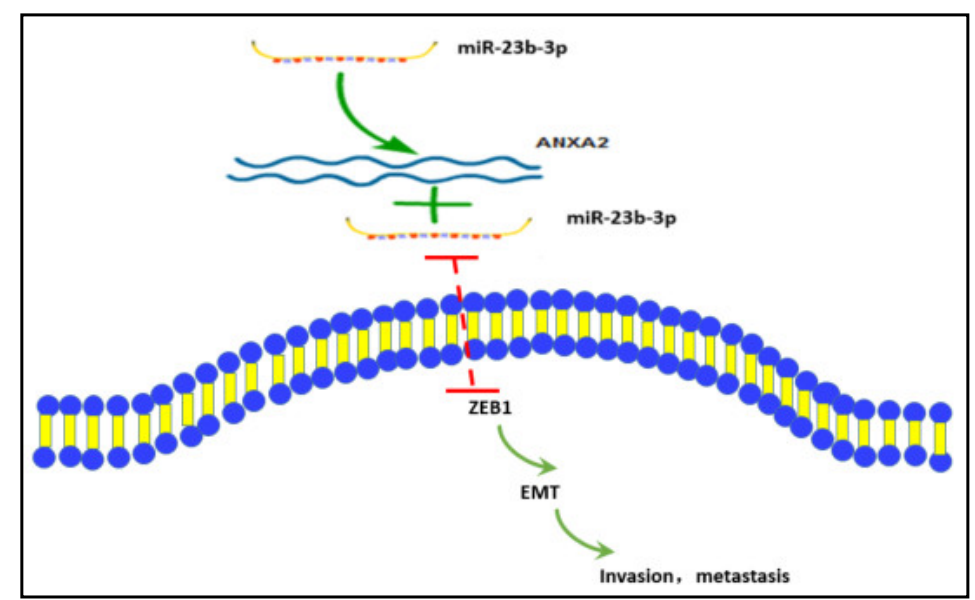

Fig. 13. MiR-23b-3p targets ANXA2 to regulate the malignant biological characteristics of PDAC. 


\section{Cellular Physiology Cell Physiol Biochem 2018;50:823-840 \begin{tabular}{ll|l} 
DOI: 10.1159/000494468 & $\begin{array}{l}\text { O } 2018 \text { The Author(s). Published by S. Karger AG, Basel } \\
\text { www.karger.com/cpb }\end{array}$
\end{tabular} \\ Wei et al.: miR-23b-3p/ANXA2 in PDAC}

has the potential to promote the proliferation, EMT, and invasion of tumor cells. Inhibition of ANXA2 will affect the expression of downstream targets and downstream signaling pathways, leading to the suppression of the malignant progression of tumors. ANXA2 has become a target in tumor therapies [40]. The direction of future research may involve investigating whether miR-23b-3p is capable of inhibiting the neural invasion of PDAC cells and subsequent metastasis through the regulation of ANXA2. Therefore, investigating the mechanisms underlying the miR-23b-3p-mediated regulation of ANXA2 in PDAC will provide clues to explore further the mechanisms of PDAC development and offer an experimental basis for its diagnosis and treatment.

\section{Acknowledgements}

The study was supported by funds from the National Natural Science Foundation of China (NSFC81560448, NSFC81560489), the Natural Science Foundation of Guangxi, China (2016GXNSFBA380039, 2014GXNSFBA118167), Guangxi Medical University Training Program for Distinguished Young Scholars (2017), the Promoting Project of Basic Capacity for University Young and Middle-aged Teachers in Guangxi (KY2016LX031), the Medical Excellence Award Funded by the Creative Research Development Grant from the First Affiliated Hospital of Guangxi Medical University, Guangxi Zhuang Autonomous Region Health and Family Planning Commission Self-financed Scientific Research project (Z20180979).

The funders had no role in study design, data collection and analysis, decision to publish, or preparation of the manuscript.

\section{Disclosure Statement}

The authors declare that they have no conflict of interests.

\section{References}

1 Li H, Hao X, Wang H, Liu Z, He Y, Pu M, Zhang H, Yu H, Duan J, Qu S: Circular RNA Expression Profile of Pancreatic Ductal Adenocarcinoma Revealed by Microarray. Cell Physiol Biochem 2016;40:1334-1344.

$>2$ Siegel RL, Miller KD, Jemal A: Cancer statistics, 2016. CA Cancer J Clin 2016;66:7-30.

3 Chen W, Zheng R, Baade PD, Zhang S, Zeng H, Bray F, Jemal A, Yu XQ He J: Cancer statistics in China, 2015. CA Cancer J Clin 2016;66:115-132.

4 Fokas E, O’Neill E, Gordon-Weeks A, Mukherjee S, McKenna WG, Muschel RJ: Pancreatic ductal adenocarcinoma: From genetics to biology to radiobiology to oncoimmunology and all the way back to the clinic. Biochim Biophys Acta 2015;1855:61-82.

-5 Brunetti O, Russo A, Scarpa A, Santini D, Reni M, Bittoni A, Azzariti A, Aprile G, Delcuratolo S, Signorile M, Gnoni A, Palermo L, Lorusso V, Cascinu S, Silvestris N: MicroRNA in pancreatic adenocarcinoma: predictive/ prognostic biomarkers or therapeutic targets? Oncotarget 2015;6:23323-23341.

-6 Lau NC LL, Weinstein EG,Bartel DP: An abundant class of tiny RNAs with probable regulatory roles in Caenorhabditis elegans. Science 2001;294:858-862.

7 Bartel DP: MicroRNAs: Genomics, Biogenesis, Mechanism, and Function. Cell 2004;116:281-297.

$>8$ Hua KT, Liu YF, Hsu CL, Cheng TY, Yang CY, Chang JS, Lee WJ, Hsiao M, Juan HF, Chien MH, Yang SF: 3'UTR polymorphisms of carbonic anhydrase IX determine the miR-34a targeting efficiency and prognosis of hepatocellular carcinoma. Sci Rep 2017;7:4466.

-9 Di Leva G, Garofalo M, Croce CM: MicroRNAs in cancer. Annu Rev Pathol 2014;9:287-314.

10 Mace TA, Collins AL, Wojcik SE, Croce CM, Lesinski GB, Bloomston M: Hypoxia induces the overexpression of microRNA-21 in pancreatic cancer cells. J Surg Res 2013;184:855-860. 


\section{Cellular Physiology Cell Physiol Biochem 2018;50:823-840

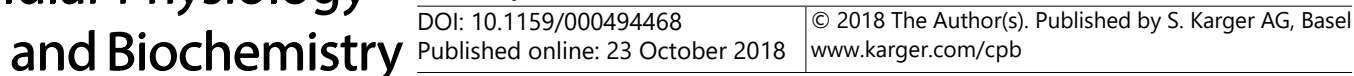 \\ Wei et al.: miR-23b-3p/ANXA2 in PDAC}

11 Li CH, Xiao Z, Tong JH, To KF, Fang X, Cheng AS, Chen Y: EZH2 coupled with HOTAIR to silence MicroRNA34 a by the induction of heterochromatin formation in human pancreatic ductal adenocarcinoma. Int J Cancer 2017;140:120-129.

12 Yang W, Yang Y, Xia L, Yang Y, Wang F, Song M, Chen X, Liu J, Song Y, Zhao Y, Yang C: MiR-221 Promotes Capan-2 Pancreatic Ductal Adenocarcinoma Cells Proliferation by Targeting PTEN-Akt. Cell Physiol Biochem 2016;38:2366-2374.

13 Li J, Zhao Y, Lu Y, Ritchie W, Grau G, Vadas MA, Gamble JR: The Poly-cistronic miR-23-27-24 Complexes Target Endothelial Cell Junctions: Differential Functional and Molecular Effects of miR-23a and miR-23b. Mol Ther Nucleic Acids 2016;5:e354.

14 Jiang-Hua Liu GC, Yi-Wu Dang, Chun-Jun Li, Dian-Zhong Luo: Expression and Prognostic Significance of IncRNA MALAT1 in Pancreatic Cancer Tissues. Asian Pac J Cancer Prev 2014;15:2971-2977.

15 Foley K, Rucki AA, Xiao Q, Zhou D, Leubner A, Mo G, Kleponis J, Wu AA, Sharma R, Jiang Q, Anders RA, Iacobuzio-Donahue CA, Hajjar KA, Maitra A, Jaffee EM, Zheng L: Semaphorin 3D autocrine signaling mediates the metastatic role of annexin A2 in pancreatic cancer. Sci Signal 2015;8:ra77.

16 Keklikoglou I, Hosaka K, Bender C, Bott A, Koerner C, Mitra D, Will R, Woerner A, Muenstermann E, Wilhelm $\mathrm{H}$, Cao Y, Wiemann S: MicroRNA-206 functions as a pleiotropic modulator of cell proliferation, invasion and lymphangiogenesis in pancreatic adenocarcinoma by targeting ANXA2 and KRAS genes. Oncogene 2015;34:4867-4878.

17 Utaijaratrasmi P, Vaeteewoottacharn K, Tsunematsu T, Jamjantra P, Wongkham S, Pairojkul C, Khuntikeo N, Ishimaru N, Sirivatanauksorn Y, Pongpaibul A, Thuwajit P, Thuwajit C, Kudo Y: The microRNA-15aPAI-2 axis in cholangiocarcinoma-associated fibroblasts promotes migration of cancer cells. Mol Cancer 2018;17:10.

18 Cao J, Liu J, Long J, Fu J, Huang L, Li J, Liu C, Zhang X, Yan Y: microRNA-23b suppresses epithelialmesenchymal transition (EMT) and metastasis in hepatocellular carcinoma via targeting Pyk2 Biomed Pharmacother 2017;89:642-650.

19 Wang P CL, Zhang J,Chen H,Fan J,Wang K,Luo J,Chen Z,Meng Z,Liu L: Methylation-mediated silencing of the miR-124 genes facilitates pancreatic cancer progression and metastasis by targeting Rac1 Oncogene 2014;33:514-524.

20 Yeung CL, Tsang TY, Yau PL, Kwok TT: Human papillomavirus type 16 E6 suppresses microRNA-23b expression in human cervical cancer cells through DNA methylation of the host gene C9orf3. Oncotarget 2017;8:12158-12173.

21 Zhang H, Hao Y, Yang J, Zhou Y, Li J, Yin S, Sun C, Ma M, Huang Y, Xi JJ: Genome-wide functional screening of miR-23b as a pleiotropic modulator suppressing cancer metastasis. Nat Commun 2011;2:554.

22 Rice MA, Ishteiwy RA, Magani F, Udayakumar T, Reiner T, Yates TJ, Miller P, Perez-Stable C, Rai P, Verdun R, Dykxhoorn DM, Burnstein KL: The microRNA-23b/-27b cluster suppresses prostate cancer metastasis via Huntingtin-interacting protein 1-related. Oncogene 2016;35:4752-4761.

-23 Alarmo EL, Havunen R, Hayrynen S, Penkki S, Ketolainen J, Nykter M, Kallioniemi A: Bone morphogenetic protein 4 regulates microRNA expression in breast cancer cell lines in diverse fashion. Genes Chromosomes Cancer 2016;55:227-236.

24 Pellegrino L, Stebbing J, Braga VM, Frampton AE, Jacob J, Buluwela L, Jiao LR, Periyasamy M, Madsen CD, Caley MP, Ottaviani S, Roca-Alonso L, El-Bahrawy M, Coombes RC, Krell J, Castellano L: miR-23b regulates cytoskeletal remodeling, motility and metastasis by directly targeting multiple transcripts. Nucleic Acids Res 2013;41:5400-5412.

25 Yan J, Jiang JY, Meng XN, Xiu YL, Zong ZH: MiR-23b targets cyclin G1 and suppresses ovarian cancer tumorigenesis and progression. J Exp Clin Cancer Res 2016;35:31.

-26 Chen S, Zong ZH, Wu DD, Sun KX, Liu BL, Zhao Y: The role of metastasis-associated in colon cancer 1 (MACC1) in endometrial carcinoma tumorigenesis and progression. Mol Carcinog 2017;56:1361-1371.

27 Wang P, Zhang J, Zhang L, Zhu Z, Fan J, Chen L, Zhuang L, Luo J, Chen H, Liu L, Chen Z, Meng Z: MicroRNA $23 \mathrm{~b}$ regulates autophagy associated with radioresistance of pancreatic cancer cells. Gastroenterology 2013;145:1133-1143.

28 Huang TT, Ping YH, Wang AM, Ke CC, Fang WL, Huang KH, Lee HC, Chi CW, Yeh TS: The reciprocal regulation loop of Notch2 pathway and miR-23b in controlling gastric carcinogenesis. Oncotarget 2015;6:1801218026. 


\section{Cellular Physiology Cell Physiol Biochem 2018;50:823-840 \begin{tabular}{l|l|l} 
DOI: 10.1159/000494468 & $\begin{array}{l}\text { O 2018 The Author(s). Published by S. Karger AG, Basel } \\
\text { www.karger.com/cpb }\end{array}$
\end{tabular} \\ Wei et al.: miR-23b-3p/ANXA2 in PDAC}

29 Ostrowski M, Carmo NB, Krumeich S, Fanget I, Raposo G, Savina A, Moita CF, Schauer K, Hume AN, Freitas RP, Goud B, Benaroch P, Hacohen N, Fukuda M, Desnos C, Seabra MC, Darchen F, Amigorena S, Moita LF, Thery C: Rab27a and Rab27b control different steps of the exosome secretion pathway. Nat Cell Biol 2010;12:19-30; sup pp 11-13.

-30 Wei T, Cong X, Wang XT, Xu XJ, Min SN, Ye P, Peng X, Wu LL, Yu GY: Interleukin-17A promotes tongue squamous cell carcinoma metastasis through activating miR-23b/versican pathway. Oncotarget 2017;8:6663-6680.

-31 Grossi I, Arici B, Portolani N, De Petro G, Salvi A: Clinical and biological significance of miR-23b and miR193a in human hepatocellular carcinoma. Oncotarget 2017;8:6955-6969.

-32 Au Yeung CL, Tsang TY, Yau PL, Kwok TT: Human papillomavirus type 16 E6 induces cervical cancer cell migration through the p53/microRNA-23b/urokinase-type plasminogen activator pathway. Oncogene 2011;30:2401-2410.

-33 Castilla MA, Moreno-Bueno G, Romero-Perez L, Van De Vijver K, Biscuola M, Lopez-Garcia MA, Prat J, Matias-Guiu X, Cano A, Oliva E, Palacios J: Micro-RNA signature of the epithelial-mesenchymal transition in endometrial carcinosarcoma. J Pathol 2011;223:72-80.

34 Verma N, Keinan O, Selitrennik M, Karn T, Filipits M, Lev S: PYK2 sustains endosomal-derived receptor signalling and enhances epithelial-to-mesenchymal transition. Nat Commun 2015;6:6064.

35 Huang TT, Ping YH, Wang AM, Ke CC, Fang WL, Huang KH, Lee HC, Chi CW, Yeh TS: The reciprocal regulation loop of Notch2 pathway and miR-23b in controlling gastric carcinogenesis. Oncotarget 2015;6:1801218026.

-36 Shirakihara T, Saitoh M, Miyazono K: Differential regulation of epithelial and mesenchymal markers by deltaEF1 proteins in epithelial mesenchymal transition induced by TGF-beta. Mol Biol Cell 2007;18:35333544.

37 Lacher MD, Shiina M, Chang P, Keller D, Tiirikainen MI, Korn WM: ZEB1 limits adenoviral infectability by transcriptionally repressing the coxsackie virus and adenovirus receptor. Mol Cancer 2011;10:91.

38 Campos-Viguri GE, Jimenez-Wences H, Peralta-Zaragoza 0, Torres-Altamirano G, Soto-Flores DG, Hernandez-Sotelo D, Alarcon-Romero Ldel C, Jimenez-Lopez MA, Illades-Aguiar B, Fernandez-Tilapa G: miR-23b as a potential tumor suppressor and its regulation by DNA methylation in cervical cancer. Infect Agent Cancer 2015;10:42.

-39 Ostenfeld MS, Jeppesen DK, Laurberg JR, Boysen AT, Bramsen JB, Primdal-Bengtson B, Hendrix A, Lamy P, Dagnaes-Hansen F, Rasmussen MH, Bui KH, Fristrup N, Christensen EI, Nordentoft I, Morth JP, Jensen JB, Pedersen JS, Beck M, Theodorescu D, Borre M et al.: Cellular disposal of miR23b by RAB27-dependent exosome release is linked to acquisition of metastatic properties. Cancer Res 2014;74:5758-5771.

40 Zheng L, Foley K, Huang L, Leubner A, Mo G, Olino K, Edil BH, Mizuma M, Sharma R, Le DT, Anders RA, Illei PB, Van Eyk JE, Maitra A, Laheru D, Jaffee EM: Tyrosine 23 Phosphorylation-Dependent Cell-Surface Localization of Annexin A2 Is Required for Invasion and Metastases of Pancreatic Cancer. PLoS One 2011;6: e19390. 